\title{
NOVOBIOCIN-TETRATHIONATE BROTH: A MEDIUM OF IMPROVED SELECTIVITY FOR THE ISOLATION OF SALMONELLAE FROM FAECES
}

\author{
BY \\ LEONARD JEFFRIES \\ From the Department of Clinical Pathology, University College Hospital, London
}

(RECEIVED FOR PUBLICATION APRIL 23, 1959)

The selective cultivation of bacteria by incorporating chemicals in the media depends on supplying a substance which either stimulates the growth of the species to be isolated or inhibits unwanted species. Tetrathionate is a good selector of Salmonellae in faeces culture, and is believed to act in both ways. Tetrathionate reducers, such as Salmonellae, flourish in broth containing it, whereas a high concentration of tetrathionate inhibits many other faecal organisms (Knox, Gell, and Pollock, 1943). Unfortunately, however, members of the Proteus group are powerful tetrathionate reducers, and when they are present selection of Salmonellae is much impaired, consequently the addition of a further selective inhibitor effective against Proteus organisms is desirable. So far no such satisfactory substance has been found: brilliant green and ox bile (Kauffmann) proved unsuccessful (Knox et al., 1942, 1943).

Antibiotics are becoming increasingly used as selective agents in culture media, but most of them are approximately equally active or inactive against Salmonellae and Proteus. Novobiocin, however, inhibits Proteus more than other Gram-negative bacilli and seemed therefore a suitable substance for trial.

\section{Materials}

Tetrathionate Broth.-This was prepared by adding two "oxoid" tablets to $10 \mathrm{ml}$. of water in a $1 \mathrm{oz}$. screw-capped bottle and bringing to the boil. The medium without iodine can be stored at room temperature for one month ; once iodine is added the complete medium is unstable.

Novobiocin-tetrathionate Broth.-Novobiocin solution containing the appropriate concentration in $0.1 \mathrm{ml}$. was added to $10 \mathrm{ml}$. of the incomplete medium, $0.2 \mathrm{ml}$. of the specified iodine solution being added before use.

Novobiocin Solution.-The sodium salt of novobiocin (Upjohn of England Ltd.) was used, and the strengths of all solutions were expressed as concentrations of pure novobiocin. As the novobiocin content varied with different batches of the salt a simple calculation was necessary each time a new sample was used. A stock solution containing novobiocin, $16,000 \mu \mathrm{g} . / \mathrm{ml}$. of water, was stored in the refrigerator.

MacConkey Agar.-Oxoid.

Desoxycholate-citrate Agar. - Southern Group Laboratory (Lewisham).

Indicator Serum Broth.-This was prepared by the method of Stokes (1955).

\section{Investigation}

For efficient selection a concentration of novobiocin is required which will inhibit most, if not all, strains of Proteus without jeopardizing the survival of small numbers of Salmonellae.

Sensitivity to Novobiocin.-The sensitivities to novobiocin of 27 strains of Proteus and of 24 strains of Salmonellae were tested by the paper disc method and by tube titration. Proteus was always more sensitive than Salmonella (Table I).

TABLE I

NOVOBIOCIN SENSITIVITY TESTS

\begin{tabular}{|c|c|c|c|c|c|}
\hline \multirow[t]{2}{*}{ Organism } & \multirow[t]{2}{*}{$\begin{array}{l}\text { No. of } \\
\text { Strains } \\
\text { Tested }\end{array}$} & \multicolumn{2}{|c|}{ Disc Test } & \multicolumn{2}{|c|}{$\begin{array}{l}\text { Tube Titration (Inhi- } \\
\text { bitory Concentration } \\
\text { of Novobiocin in } \\
\mu \mathrm{g} . / \text { Iml. Indicator } \\
\text { Serum Broth) }\end{array}$} \\
\hline & & $\begin{array}{c}\text { Sensi- } \\
\text { tive }\end{array}$ & $\begin{array}{c}\text { Resis- } \\
\operatorname{tant}\end{array}$ & Average & Range \\
\hline $\begin{array}{l}\text { Salmonella species } \\
\text { P. morganii } \\
\text { P. mirabilis }\end{array}$ & $\begin{array}{r}24 \\
5 \\
13 \\
9 \\
5 \\
5 \\
4\end{array}$ & $\begin{array}{r}5 \\
13 \\
9 \\
= \\
=\end{array}$ & $\begin{array}{l}24 \\
= \\
5 \\
5 \\
4\end{array}$ & $\begin{array}{r}>2,400 \\
85 \\
170 \\
160\end{array}$ & $\begin{array}{c}1,600-3,200 \\
25-200 \\
25-400 \\
25-400\end{array}$ \\
\hline
\end{tabular}

Effects of Concentrations of Novobiocin in Tetrathionate Broth upon Growth of Salmonellae.-A plate viable count (Miles and Misra, 1938) was made on blood agar from an overnight broth culture of Salmonella paratyphi $B$. Drops from the highest dilutions were seeded into bottles containing 
TABLE II

RECOVERY OF SALMONELLAE FROM ARTIFICIALLY INFECTED FAECES SUSPENSIONS CONTAINING PROTEUS

\begin{tabular}{|c|c|c|c|c|c|c|c|}
\hline \multirow{2}{*}{$\begin{array}{c}\text { Experi- } \\
\text { ment }\end{array}$} & \multirow{2}{*}{ Salmonella } & \multicolumn{2}{|c|}{ Proteus } & \multicolumn{4}{|c|}{$\begin{array}{l}\text { Minimal Nos. of Salmonellae/ml. of Faeces Suspension Detectable } \\
\text { after Culture in }\end{array}$} \\
\hline & & Strain & $\begin{array}{c}\text { Approximate } \\
\text { No./ml. } \\
\text { Faeces }\end{array}$ & $\begin{array}{l}\text { Tetrathionate } \\
\text { Broth }\end{array}$ & $\begin{array}{l}\text { Proteus } \\
\text { Present }\end{array}$ & $\begin{array}{l}\text { Novobiocin- } \\
\text { tetrathionate } \\
\text { Broth }\end{array}$ & $\begin{array}{l}\text { Proteus } \\
\text { Present }\end{array}$ \\
\hline $\begin{array}{l}a \\
b \\
c \\
d \\
e \\
f \\
g \\
h\end{array}$ & \begin{tabular}{l}
\multicolumn{1}{c}{ Schwarzengrund } \\
$\quad$, \\
Typhi-murium \\
Paratyphi B \\
Enteritidis \\
Thompson \\
Anatum
\end{tabular} & $\begin{array}{l}\text { Morganii }(11,229) \\
\text { Vulgaris' } \\
\text { Mirabilis }(7,406) \\
\text { Morganii } \\
\text { Miräbilis }\end{array}$ & $\begin{array}{r}5,000 \\
266,000 \\
5,000 \\
5,000 \\
5,000 \\
5,000 \\
5,000 \\
5,000\end{array}$ & $\begin{array}{r}42 \times 10^{5} \\
>28 \times 10^{3} \\
42 \text { or less } \\
>140 \times 10^{6} \\
88 \times 10^{6} \\
22 \times 10^{4} \\
30 \text { or less } \\
34 \times 10^{2}\end{array}$ & $\begin{array}{l}++++ \\
+++ \\
+++ \\
+++++ \\
++++ \\
++++ \\
+++++ \\
+++++\end{array}$ & $\begin{array}{c}7 \\
28 \text { or less } \\
42 \text { or less } \\
140 \text { or less } \\
88 \times 10^{4} \\
22 \times 10^{4} \\
30 \text { or less } \\
35 \text { or less }\end{array}$ & $\begin{array}{c}+ \\
++++ \\
++\end{array}$ \\
\hline
\end{tabular}

+ Indicates the number of bottles in which Proteus survived.

tetrathionate broth and into bottles containing different dilutions of novobiocin in tetrathionate broth. Each concentration of the organism was tested in triplicate in each medium. The test was repeated with the same strain of Salmonella paratyphi $B$ and also with a strain of Salmonella enteritidis.

As a result of these tests a concentration of $40 \mu \mathrm{g} . / \mathrm{ml}$. novobiocin in tetrathionate broth appeared to be the most suitable, since there was no inhibition when growth of about 3 to 30 organisms was compared in tetrathionate broth and tetrathionate broth plus $40 \mu \mathrm{g}$. $/ \mathrm{ml}$. novobiocin.

Suppression of Proteus by Tetrathionate Containing Novobiocin.-Diluted overnigint broth cultures of four strains of Proteus were seeded into triplicate bottles of nutrient broth, tetrathionate broth, and novobiocin tetrathionate broth. Novobiocin at a concentration of $40 \mu \mathrm{g} . / \mathrm{ml}$. completely suppressed growth of an inoculum of about 70 organisms during incubation overnight.

Stability of Novobiocin in Selective Media.-It seemed likely that if novobiocin proved to be a useful selector in tetrathionate broth it might also prove of value in other enrichment media for Salmonellae. Its stability was therefore tested in tetrathionate broth, Selenite-F medium, and in the medium of Rappaport, Konforti, and Navon (1956).

The drug was stable at a concentration of $40 \mu \mathrm{g} . / \mathrm{ml}$. in all three media for at least 48 hours at $37^{\circ} \mathrm{C}$. and for at least one month at $4^{\circ} \mathrm{C}$. There was no loss of potency in tetrathionate broth on storage without iodine at room temperature for one month. Novobiocin at a concentration of $40 \mu \mathrm{g} . / \mathrm{ml}$. tetrathionate broth was used in all subsequent experiments.

Comparison of Tetrathionate and Novobiocintetrathionate Broths for Recovery of Salmonellae in Presence of Proteus from Artificially Infected Faecal Suspensions.-An emulsion was prepared in $40 \mathrm{ml}$. of water of approximately $5 \mathrm{~g}$. of faeces from a patient who was not receiving antibiotics. A dilution of an overnight broth culture of Proteus was added to give approximately 5,000 bacilli $/ \mathrm{ml}$., and $5 \mathrm{ml}$. of this suspension was delivered into each of $5 \times 1 \mathrm{oz}$. screw-capped bottles. Counted numbers of Salmonellae were then added to give a series of bottles containing faeces, a constant number of Proteus, and varying numbers of Salmonellae. Each bottle was shaken thoroughly on a mechanical shaker, and $1 \mathrm{ml}$. quantities from each bottle were cultured in tetrathionate broth with and without novobiocin.

After overnight incubation subcultures were made on MacConkey agar and two colonies of each type of non-lactose-fermenter were tested for urease production. Those which proved to be urease negative were tested by slide agglutination, using the appropriate Salmonella antiserum. As the properties and colonial appearances of the Salmonella strains were well known, final identification by tube agglutination was considered to be superfluous. The number of each type of non-lactose-fermenting colony examined was purposely limited so that the chance of isolating Salmonellae should be approximately the same as it would be in routine examinations of faeces.

Table II shows that Salmonellae representative of groups $\mathbf{B}, \mathrm{C}, \mathrm{D}$, and $\mathbf{E}$ can be isolated more successfully by enrichment in novobiocin-tetrathionate broth than in plain tetrathionate broth when Proteus is present.

Group A was not investigated because the strain of Salmonella paratyphi $A$ examined proved to be inhibited by tetrathionate broth, which confirmed the findings of Banwart and Ayres (1953).

Comparison of the results of experiments (a) and (b) shows that the efficiency of novobiocin-tetrathionate broth may be unaffected by a 50 -fold increase in the number of Proteus.

In experiments (c), (f), and (g), novobiocintetrathionate broth did not detect smaller numbers of Salmonellae than plain tetrathionate broth. The only non-lactose-fermenters recovered from novobiocintetrathionate broth, however, were Salmonellae, and growths were always heavier than those from tetrathionate broth.

Since it was shown in a separate experiment that small numbers of the Salmonella enteritidis strain used in experiment (f) survived $40 \mu \mathrm{g}$. $/ \mathrm{ml}$. novobiocin 
in tetrathionate broth the poor growth of this Salmonella was not due to a harmful effect of novobiocin.

Incorporation of Novobiocin in Desoxycholatecitrate-agar. - Desoxycholate-citrate-agar (D.C.A.) suffers from the disadvantage that it readily supports the growth from faeces of most strains of Proteus. It was therefore considered worth while to investigate the possibility of incorporating novobiocin in D.C.A. in such concentrations that Proteus would be inhibited and the medium would not be rendered more toxic for Salmonellae and Shigellae.

In order to test the ability of desoxycholate-citrateagar to support the growth of the test organisms, 18-hour broth cultures were diluted $1 / 100$, and one loopful was spread over a segment of a D.C.A. plate, which was then incubated for 18 hours. Of 14 strains of Proteus, nine grew well, four grew poorly, and one failed to grow. Good growth was obtained with 14 Shigella strains ( $S$. sonnei six, $S$. boydii two, $S$. flexneri six) and five strains of Salmonellae, including one strain of Salmonella typhi.

Growth on Desoxycholate-citrate-agar Containing Different Concentrations of Novobiocin.Desoxycholate-citrate-agar containing novobiocin, $100 \mu \mathrm{g} . / \mathrm{ml}$., was inoculated with dilute broth cultures. It was found that this medium, although completely inhibitory to all the Proteus strains tested, was also markedly inhibitory to the strains of Salmonellae and Shigella sonnei. Desoxycholate-citrate-agar plates were then prepared containing novobiocin in concentrations from $50 \mu \mathrm{g} . / \mathrm{ml}$. to $2 \mu \mathrm{g} . / \mathrm{ml}$. of medium and inoculated with dilute broth cultures of the following organisms (the number of strains tested is shown in brackets): $S$. boydii (2), S. sonnei (2), $S$. flexneri (6), Salm. thompson (1), Salm. typhi (1), $P$. vulgaris (1), P. mirabilis (2), P. morganii (1). Plates were incubated overnight.

The highest concentration of novobiocin in D.C.A. which did not affect the growth of the Shigellae and Salmonellae tested was $16 \mu \mathrm{g} . / \mathrm{ml}$. of medium, and this did not prevent the growth of three-quarters of the Proteus strains. Desoxycholate-citrate-agar containing $32 \mu \mathrm{g}$. novobiocin $/ \mathrm{ml}$. medium, whilst inhibiting the growth of half the strains of Proteus, was markedly inhibitory to one strain of $S$. flexneri, slightly inhibitory to one strain each of $S$. sonnei and $S$. boydii, and without effect upon growth of Salm. thompson and Salm. typhi, but $50 \mu \mathrm{g}$. novobiocin $/ \mathrm{ml}$. medium completely inhibited growth of all strains of Proteus and one strain of Salm. typhi.

Thus the lowest concentration of novobiocin tested in D.C.A. which effectively inhibited Proteus was also markedly inhibitory to Shigellae and Salm. typhi, so that the medium is unsatisfactory for routine use.

Proteus Suppression in Routine Faeces Cultures in Novobiocin-tetrathionate Broth.-During a threemonth trial, in which $0.5 \mathrm{ml}$. of a suspension of each specimen of faeces examined was inoculated into both novobiocin-tetrathionate broth and tetrathionate broth, no Salmonellae were encountered. Novobiocin-tetrathionate broth effectively suppressed Proteus when the specimens contained insufficient numbers to give profuse growths on direct cultures.

\section{Discussion}

In a discussion of the comparative merits of Salmonella enrichment media Rappaport et al. (1956) assigned to their new medium a "valency coefficient" (Lang, 1952, 1954), showing it to be superior to the medium of Bierbrauer: these results were based on tests in which only one strain of each of two organisms was used.

From the experiments (a) and (c) with tetrathionate broth (Table II), it will be seen that when two different strains of Proteus were tested with a single strain of Salmonella markedly different valency coefficients were obtained.

The term "valency coefficient" is thus shown to be misleading, since its value will vary according to the strains of organisms tested. The conclusions of Rappaport et al. concerning the comparative selectivity of their medium may therefore be erroneous.

Although the value of enrichment media for isolating members of the Salmonella group is established, there is little agreement upon the relative merits of the many types and their modifications' which have been described. Experimental work has shown that no one medium may be suitable for all members of this large genus and that the maximum number of Salmonella isolations is made when several media are used simultaneously (Collard and Unwin, 1958).

It seems likely that the addition of novobiocin would improve the selectivity of all liquid media for Salmonellae, but controlled trials in each medium would be required, as the combination of novobiocin with different selective agents might inhibit Salmonellae, as was found in the tests described above with D.C.A. As tetrathionate broth is one of the enrichment media commonly used in this country it was chosen for trial in the first instance.

A comparison of the proposed medium with other enrichment media for the isolation of Salmonellae from faeces of infected patients was not possible, owing to the infrequency of Salmonella infections in this area.

\section{Summary}

Of the non-lactose-fermenting Gram-negative bacilli encountered in faeces, members of the Proteus group are the most sensitive and Salmonellae are amongst the most resistant to novobiocin. 

Tetrathionate broth containing $40 \mu \mathrm{g}$.
novobiocin $/ \mathrm{ml}$. medium has proved superior to plain tetrathionate broth as an enrichment medium for the isolation of Salmonellae from faeces artificially infected with known numbers of Salmonellae and Proteus.

Novobiocin at a concentration of $40 \mu \mathrm{g} . / \mathrm{ml}$. medium in tetrathionate broth remained stable for at least 48 hours at $37^{\circ} \mathrm{C}$., and for one month at room temperature. Results of stability tests in other enrichment media are reported.

The criteria used for the quantitative comparison of enrichment media are discussed, and the term "valency coefficient," as used by Rappaport et al., is shown to be misleading.

Desoxycholate-citrate-agar containing novobiocin in a concentration sufficiently high to inhibit Proteus is also inhibitory to Shigellae and
Salm. typhi and is therefore not useful for the direct culture of faeces.

To Professor Wilson Smith, F.R.S., and Dr. E. J. Stokes I am indebted for helpful criticism and guidance during the course of this investigation and in the presentation of the results. I am also grateful to Dr. Joan Taylor and Dr. K. P. Carpenter for providing Salmonella and Shigella strains, and to Dr. A. R. H. Hicks, of Upjohn of England Ltd., for an ample supply of novobiocin.

\section{REFERENCES}

Banwart, G. J., and Ayres, J. C. (1953). Appl. Microbiol., 1, 296.

Collard, P., and Unwin, M. (1958). J. clin. Path., 11, 426.

Knox, R., Gell, P. G. H., and Pollock, M. R. (1942). J. Path. Bact., 54, 469.

Lang, K. (1952). Zbi. Bakt., I. Abt. Orig., 157, 565.

Lang, K. (1954). Ibid., 161, 165

Miles, A. A., and Misra, S. S. (1938). J. Hyg. (Camb), 38, 732

Rappaport, F., Konforti, N., and Navon, B. (1956). J. clin. Path., $9,261$.

Stokes, E. J. (1955). Clinical Bacteriology, 1st ed. Arnold, London. 